\title{
A visão de profissionais de saúde sobre a negligência dos pais para com seus filhos
}

\author{
Health professionals view of parents neglect of their children
}

\author{
Regina Sueli de Sousa* \\ Mariana Gonçalves Dourado**
}

\section{Resumo}

O objetivo desse estudo visa compreender a percepção dos profissionais de saúde sobre a negligência dos pais para com seus filhos, por meio de pesquisa bibliográfica de produções textuais elaboradas por psicólogos, enfermeiros, assistentes sociais e médicos pediatras. Trata-se de uma pesquisa qualitativa, exploratória e indutiva. Foram selecionados nove textos, dentre artigos, dissertações e manuais de orientação. Dentre os textos escolhidos, foram selecionadas algumas partes que discorriam sobre a categoria negligência, a partir daí foram interpretados considerando toda a discussão elaborada no texto de cada autor. Conclui-se que a negligência é um grave problema de saúde pública, mesmo assim, poucas pesquisas foram produzidas especificamente sobre o tema em todas as categorias profissionais pesquisadas. Além disto, percebeu-se que filhos de famílias pobres são mais vulneráveis a atos de negligência parental.

Palavras-chave: Negligência, Crianças e Adolescentes, Profissionais de saúde.

\begin{abstract}
The objective of this study is to understand the perception of health professionals about the neglect of parents towards their children, through a bibliographical research of textual productions elaborated by psychologists, nurses, social workers and pediatricians. It is a qualitative, exploratory and inductive research. Nine texts were selected, including articles, dissertations and guidance manuals. Among the chosen texts, some parts were selected that dealt with the neglect category, and from there they were interpreted considering all the discussion elaborated in the text of each author. It is concluded that neglect is a serious public health problem, even so, few researches were specifically produced on the subject in all professional categories surveyed. In addition, it has been realized that children from poor families are more vulnerable to acts of parental neglect.
\end{abstract}

Keywords: Neglect, Children and Adolescents, Health professionals.

\footnotetext{
* Graduação em Serviço Social pela Pontifícia Universidade Católica de Goiás (PUC Goiás, 1985), mestrado em Política Social pela Universidade de Brasília (UnB, 1997) e doutorado em Educação Escolar pela Universidade Estadual Paulista Júlio de Mesquita Filho (UNESP-Marília, 2002). Professora Adjunto I do Curso de Serviço Social da Universidade Federal de Goiás (UFG). Professora do Curso da Residência Multiprofissional em Saúde do Hospital das Clínicas (HC/UFG), na área de Serviço Social.

** Bacharel em Serviço Social (PUC-GO). Especialização em andamento- Saúde Materna- Infantil (HC-UFG/Ebserh)
} 


\section{Introdução}

A palavra negligência, originária do latim negligentia (desprezar, desconsiderar), segundo definição do dicionário Michaelis (2019), significa falta de diligência; descuido, desleixo; incúria, preguiça; desatenção, menosprezo para com algo ou alguém, no caso desse estudo, esta palavra será tratada como uma categoria, advinda de uma das formas de violência intrafamiliar, isto é, a violência que ocorre dentro de residências e que envolve os membros da família (BERBERIAN, 2015).

Faz-se necessário saber que a violência intrafamiliar é um problema de saúde pública, obstáculo para o desenvolvimento social e econômico do país, além de ser uma forma violadora dos direitos humanos. Qualquer tipo de abuso praticado dentro do ambiente familiar contra um de seus membros, todas as ações e omissões que prejudiquem o bemestar, a integridade física, psicológica ou a liberdade de algum membro da família, pode ser caracterizada como violência intrafamiliar, sendo a negligência familiar uma forma de violência (BRASIL, 2001).

A família ressurge na contemporaneidade como objeto central de elaboração de planos, programas e projetos no contexto das políticas sociais nacionais e internacionais. É preciso pontuar que esta centralidade possui pontos bastante positivos, valorizando o direito à convivência familiar e comunitária, a autonomia dos sujeitos e responsabilizando mutualmente os membros da família uns pelos outros (TEIXEIRA, 2015). Todavia, como afirma a Política Nacional de Assistência Social (PNAS), pressupor que a família tem a função de prevenir, proteger, promover e incluir seus membros, envolve, inicialmente, efetivar condições para ela ter sustentabilidade nestes atos (BRASIL, 2004).

O interesse em desenvolver esse estudo foi instigado em razão de diversas solicitações de profissionais de saúde para que o Serviço Social atendesse aos casos relacionados à negligência à criança e ao adolescente ou à suspeita de negligência. Os assistentes sociais do Eixo Materno-Infantil da Residência Multiprofissional, trabalham bem próximos de expressões da questão social relacionadas às crianças, aos adolescentes, às gestantes e à família, sendo a negligência familiar uma das expressões da questão social. Rotineiramente, percebeu-se que os profissionais de saúde possuem visões diferenciadas sobre o que é negligência à criança e ao adolescente, às vezes visões precipitadas, outrora 
tardias, pois a suspeita da presença de negligência parental surge apenas quando o quadro clínico da criança ou do adolescente é bastante agravado.

Em outros termos, devido às constantes demandas para realizar avaliações sobre negligência, percebeu-se a necessidade de aprofundar o conhecimento sobre esta temática. Acredita-se que este estudo será relevante para todos os profissionais da área da saúde que lidam com o público infanto-juvenil.

\section{Método}

Trata-se de um estudo qualitativo, exploratório e indutivo a respeito da visão de profissionais de saúde sobre o que é negligência dos pais para com seus filhos, o estudo foi fundamentado em pesquisas bibliográficas que discutiam o conceito negligência. Realizou-se levantamento bibliográfico em base de dados de artigos científicos: SciELO, e no Portal de Periódicos CAPES/MEC. As seguintes palavras foram utilizadas para realizar a busca: negligência, crianças e adolescentes, saúde, profissionais e maus-tratos. Não houve delimitação de tempo para realizar a busca na base de dados, visto que, utilizou-se o critério de conveniência para a escolha dos artigos.

Foram selecionados nove textos, incluindo artigos e dissertações de mestrado, e manuais de procedimentos que tratavam sobre negligência, ou maus-tratos. Observou-se que alguns títulos utilizam o termo maus-tratos e discorrem sobre a conceito negligência. Estes foram organizados por categoria profissional, sendo selecionadas produções textuais das seguintes categorias profissionais: Serviço Social, Enfermagem, Psicologia e Medicina Pediátrica. Selecionou- se três textos elaborados por psicólogos, visto que há diversas produções textuais sobre a categoria negligência advindas desses profissionais. Das outras categorias profissionais foram selecionados dois textos, devido à dificuldade de encontrar estudos referentes a esta temática.

Por fim, foi feita uma interpretação sobre qual perspectiva esses profissionais consideravam a categoria negligência. Os resultados e a discussão serão apresentados de forma descritiva.

Breve abordagem sobre a conjuntura econômica e sobre os direitos das crianças e dos adolescentes 
Considerou-se relevante realizar uma breve análise socioeconômica brasileira antes de iniciar a discussão dos dados coletados, visto que o processo saúde-doença perpassa pela condição socioeconômica das pessoas. Isto é, algumas doenças são motivadas ou agravadas pelas condições culturais, ambientais, econômicas, pelas relações de trabalho, entre outros fatores.

Dados do Instituto Brasileiro de Geografia e Estatística (IBGE) por meio da Pesquisa Nacional por Amostra de Domicílios Contínua (PNAD Contínua, 2017) indicou que atualmente, no Brasil, há cerca de 13 milhões de pessoas desempregadas. Agregado a este dado foi constatado que a quantidade de trabalhadores informais aumenta substancialmente "em termos percentuais, os trabalhadores formais representaram $61,2 \%$ em 2016 , enquanto os informais atingiram 38,8\%" (IBGE, 2017, p. 15) dados referentes à totalidade de trabalhadores brasileiros. Pontua-se que a condição de trabalhador informal, em suma, não fornece ao trabalhador a condição de segurado da Previdência Social, ou seja, não Ihe fornece acesso ao seguro social, para casos de desemprego ou adoecimento.

O Brasil é um dos países mais desiguais do mundo, de acordo com Oxfam (2018, p. 16) "no comparativo global, em matéria de desigualdade de renda caiu-se, em 2017 , da posição de 10 para 9 país mais desigual do planeta". Apesar da conjuntura caótica, o Sistema Único de Saúde (SUS), criado em 1990, mantém dentre seus princípios, expressos na Lei 8.080/90, a universalidade, a equidade e a integralidade, princípios estes conquistados pelos movimentos sociais agregados à classe trabalhadora. Destaca-se que a conjuntura socioeconômica atual, vulnerabiliza ainda mais aqueles que já são vulneráveis, faz-se referência às crianças e aos adolescentes que chegam a unidade hospitalar por conta de algum agravo em sua saúde. A análise da $\operatorname{Oxfam~(2018,~p.~16),~registra~que,~}$

Em 2016, pela primeira vez desde 1990, o Brasil registrou alta na mortalidade infantil, que subiu de 13,3 , em 2015 , para 14 mortes por mil habitantes (4,9\% a mais que o ano anterior). Além disso, houve uma escalada da pobreza no país, retrato de injustiças que há pouco tempo estavam em trajetória de superação.

Apesar da universalidade do SUS, há hegemonia em estudos sobre dados sociodemográficos de usuários desse Sistema em afirmar que seus usuários são pertencentes às camadas mais pobres da população, a maioria são: mulheres, pretos e pardos, e possuem 
baixa escolaridade (RIBEIRO, et al., 2006; SILVA, et al., 2011). Além disso, por ser um sistema de saúde público, há um errôneo imaginário que foi destinado aos pobres. Como mencionado, o SUS foi criado para ser universal, isto é, para todos. Contudo, apresenta inúmeras dificuldades para fornecer um atendimento de qualidade para toda a população, esta é uma das razões de ele ser utilizado, majoritariamente, pelos pobres. Enquanto os que podem pagar são atendimentos pela rede de saúde privada, principalmente por meio de convênios e/ou cooperativas.

Sabe-se que na década de 1980, o Brasil, passou por momentos de importantes conquistas sociais para os cidadãos brasileiros, como a promulgação em 1988 da Constituição Federal da República Federativa do Brasil (CF), que em seu artigo 227 afirma que a família, a sociedade e o Estado, devem assegurar à criança e ao adolescente, com absoluta prioridade, todos os direitos e garantias fundamentais à vida, ressaltando que estas instituições devem mantê-las protegidas de qualquer forma de negligência, discriminação, exploração, violência, crueldade e opressão. Nesse sentido, foi introduzido na legislação brasileira a doutrina de proteção integral $^{1}$ à criança e ao adolescente.

O Brasil constituiu ao longo de sua história um vasto arcabouço legal referente à proteção dos direitos das crianças e dos adolescentes, o Estatuto da Criança e do Adolescente (ECA) de 1990 é considerado um grande marco na história deste país relacionado à proteção dos menores de 18 anos. O ECA trouxe a concepção de criança e adolescente como sujeito de direitos, isto é, até 1990, no Brasil não havia legislação que os categorizasse como pessoas que possuem direitos e deveres. Além desse enorme avanço, o Estatuto, regulamentou o mencionado art. 227 da Constituição Federal de 1988, sendo assim, há corresponsabilidade do Estado, da sociedade e da família para que todos os direitos e garantias fundamentais das crianças e dos adolescentes sejam viabilizados.

Teixeira (2015) afirma que no começo da década de 1990, a centralidade das políticas públicas foi a criança na família. Como mencionado, a promulgação da CF (1988) e o advento da ECA (1990) possibilitou o enfoque nas famílias. A autora refere que não se tratou de especificar o cuidado para com a família, e sim do cuidado da criança dentro da família. Para Martin (1995, p. 70, grifo do autor),

\footnotetext{
${ }^{1}$ A doutrina de proteção integral é completamente oposta à doutrina da situação irregular, esta vigorava antes do ECA no Código de Menores de 1979, para esta doutrina, os menores de idade não eram sujeitos de direitos.
} 
A família surge, assim, como um lugar de protecção [sic], como um escudo contra a violência da adversidade contemporânea, como uma «manancial» de solidariedades alternativas às do Estado, como um tecido de laços sociais elementares.

As políticas sociais atualmente se apresentam com características de responsabilidades compartilhadas, trata-se do chamado welfare mix, este modo de fazer política social combina recursos, e meios mobilizáveis junto do Estado, do mercado, das organizações sociais sem fins lucrativos, da família entre outros. Com esta atual modalidade para atender às demandas sociais, o Estado deixa de ser o principal responsável pelo bemestar social, este papel cabe também às inciativas privadas e à família. Diante disso um questionamento é levantado: em uma conjuntura de crise econômica, como se apresenta a realidade brasileira, na qual prevalece a ausência de trabalho remunerado; as famílias pobres conseguem suportar, mais do que já suportam, essa responsabilidade? (MARTIN, 1995). Este questionamento é fundado sob a perspectiva da legislação brasileira, em que se também responsabiliza o Estado pelo bem-estar da população, e para além disto, destaca-se a alta carga tributária brasileira e os deficitários retornos destes tributos à população.

\section{Resultados e discussão}

Em 1997, o Ministério da Saúde descreveu o que era negligência, tendo por referência Azevedo e Guerra, (1989); Claves, (1992); Ruiz, (1990), afirmando que negligência era a omissão da família para prover às necessidades físicas e emocionais de uma criança e de um adolescente, entretanto ponderaram que essas omissões só poderiam ser consideradas abusivas quando não eram motivadas por carências de recursos socioeconômicos (BRASIL, 1997).

Tabela 1 - Classificação dos textos analisados quanto ao título, área profissional, ano, e a modalidade de textos, publicados entre 2001 a 2018.

\begin{tabular}{|l|c|c|c|}
\hline \multicolumn{1}{|c|}{ Título } & Área & Ano & Modalidade \\
\hline $\begin{array}{l}\text { Serviço Social e avaliações de negligência: debates no campo } \\
\text { da ética profissional. }\end{array}$ & Serviço Social & 2015 & Artigo \\
\hline $\begin{array}{l}\text { Desvelando a violência contra as crianças em um hospital } \\
\text { universitário: desafios para o Serviço Social. }\end{array}$ & Serviço Social & 2010 & Artigo \\
\hline $\begin{array}{l}\text { Características da violência contra a criança em uma capital } \\
\text { brasileira. }\end{array}$ & Enfermagem & 2012 & Artigo \\
\hline $\begin{array}{l}\text { Violência doméstica infantil: abordagem da enfermagem } \\
\text { Violência e saúde de adolescentes e jovens como o pediatra } \\
\text { deve proceder? }\end{array}$ & Enfermagem & 2012 & Artigo \\
\hline
\end{tabular}




\begin{tabular}{|l|c|c|c|}
\hline $\begin{array}{l}\text { Guia de atuação frente a maus-tratos na infância na } \\
\text { adolescência. }\end{array}$ & Pediatria & 2001 & $\begin{array}{l}\text { Manual de } \\
\text { orientação }\end{array}$ \\
\hline $\begin{array}{l}\text { Negligência infantil: estudo comparativo do nível } \\
\text { socioeconômico, estresse parental e apoio social. }\end{array}$ & Psicologia & 2010 & Artigo \\
\hline $\begin{array}{l}\text { Crianças negligenciadas: a face (in) visível da violência Família. } \\
\text { Negligência infantil: a modalidade mais recorrente de maus- } \\
\text { tratos. }\end{array}$ & Psicologia & 2006 & Dissertação \\
\hline
\end{tabular}

Fonte: dados pesquisados pela autora.

Para a Sociedade Brasileira de Pediatria (SBP, 2001), a negligência é uma das formas de maus-tratos à criança mais comuns. Indicam dois critérios como característica da negligência: a cronicidade e a omissão, o primeiro refere-se à continuidade de algum indicador que aponte para negligência e o segundo, a omissão, refere-se ao não provimento de alguma necessidade da criança. Esses autores consideram, ainda que, o Estado, a sociedade e a família são os responsáveis pelos cuidados da criança. A respeito da realidade socioeconômica da família, a SBP pontua,

Mesmo em condições de pobreza, a família possui um estoque de possibilidades para prover os cuidados de que a criança necessita. Esse "padrão" é observável, na prática, pela comparação com os cuidados que outras famílias, em mesma situação de pobreza, dispensam aos seus filhos (SBP, 2001, p. 29, grifo do autor).

A SBP (2018), em um Manual de orientação voltado aos pediatras, discute os tipos de violências contra crianças, afirmando que a negligência é o tipo de violência mais diagnosticada no Brasil. Detém-se em citar formas de concretização de negligência: atraso na busca de cuidados à saúde sem justificativa; indiferença afetiva, má higiene, abandono; falta de supervisão escolar adequada, entre outros.

Percebe-se que os dois textos abordados de autoria da SBP estão focalizados na descrição de formas de negligência, deixando de realizar análises aprofundadas sobre a multicausalidade de atos de violência, ou da negligência como uma ramificação da categoria violência. Comparar famílias pobres que conseguem cuidar de seus filhos e famílias pobres que não conseguem cuidar de seus filhos por "padrões" é algo que necessita ser repensado, visto que a subjetividade das famílias é algo que não deveria ser analisado por padrões, e sim caso a caso.

Seger, Caldart, e Grossi (2010), em um estudo sobre violência contra crianças apresentadas em um hospital, a partir da percepção do Serviço Social, indicam alguns dados sociodemográficos. Ao apontarem que a negligência é a forma mais comum de violência 
contra crianças dentro do ambiente hospitalar, elas a categorizam como intencional e não intencional. Foram indicadas algumas formas de negligência: o não cumprimento das recomendações referentes à prevenção de doenças, a falta de cuidados apropriados, má alimentação dos filhos, despreocupação com o desenvolvimento adequado dos filhos, exposição da criança às drogas, e falta de proteção em relação aos perigos presentes no meio ambiente.

Berberian (2015), em seu estudo sobre a avaliação do Serviço Social em casos de negligência, afirma que as produções da profissão nesta temática ainda são incipientes, levantando a preocupação sobre o uso do conceito negligência. Sua preocupação consiste na possibilidade de o termo negligência está sendo usado pela categoria profissional sob um viés moralista.

A autora afirma que o Serviço Social apresenta expressiva quantidade de profissionais que atuam na área da infância e da juventude, diante disto, a profissão se legitima historicamente por desenvolver atividades em prol dos direitos deste público. Entretanto, a observação empírica, sobre a avaliação de assistente sociais em casos de negligência, demonstra que não havia consistência nos recursos e métodos utilizados em um atendimento, ou seja,

\footnotetext{
Percebemos no trabalho profissional a repetição de uma prática que define diferentes eventos envolvendo os sujeitos a partir do conceito negligência, sem a radical problematização e reflexão do conteúdo desse conceito e da forma de seu uso. [...] situações são entendidas como negligência sem qualquer recorrência à totalidade desses sujeitos, desconsiderando sua concreta inserção em uma sociedade que é real e se configura de maneira objetiva, com rebatimentos objetivos (BERBERIAN, 2015, p. 50).
}

De acordo com a autora, as diversas expressões da questão social estão presentes no cotidiano de famílias que sobrevivem às mais variadas condições de precariedade. O desemprego/subemprego, o uso abusivo de álcool e outras drogas, a frequente exposição às violências são alguns dos exemplos citados. Diante destas condições mínimas de sobrevivência, as famílias atendidas pelo Serviço Social são questionadas sobre a forma de proteção dada a seus filhos, sendo responsabilizadas, completamente, pela oferta de cuidados e de serviços necessários às crianças e aos adolescentes. Dessa forma, se ignora que o Estado 
também é responsável pela proteção do público infanto-juvenil, assim como, preconiza o sistema de garantia de direitos.

No que concerne aos textos que referenciaram a categoria negligência, a partir dos estudos de psicólogos, destaca-se o estudo de Bazon et al. (2010), no qual as autoras realizam um estudo comparativo sobre o nível socioeconômico, estresse parental e apoio social. Ao Comparem as famílias negligentes com famílias não negligentes, foi percebido que as famílias negligentes possuíam proles maiores, e foram caracterizadas por terem renda econômico baixa, muitas sobreviviam com benefícios sociais. A maioria dos cuidadores de crianças negligenciadas estavam com baixa autoestima; houve frequência no uso de álcool e outras drogas; além de a rede sociais desses cuidadores se apresentar mais frágil.

Pasian et al. (2013) elaboraram um estudo visando expor definições sobre a categoria negligência, realizaram uma síntese sobre o que consideram ser negligência: quando os pais, não têm vontade/disposição ou capacidades psicológicas para cuidar de seus filhos, diante disto, não solicitam ajuda de quem deve ou pode ajudar a suprir alguma necessidade da criança ou do adolescente.

As autoras trabalharam com diversos pesquisadores, a fim de alertar as graves consequências resultantes nos filhos de pais negligentes. Citam, por exemplo, problemas desenvolvimentais múltiplos, capacidades adaptativas sobrecarregadas; nas escolas podem apresentar dificuldades de aprendizagem e comportamento, e mais uma série de outras consequências negativas (PESIAN et al., 2013).

Cabe salientar que quando se fala em crianças e adolescentes negligenciados na atenção terciária da saúde, comumente se refere aos pacientes com doenças crônicas, e estas doenças podem exigir uma série de cuidados rigorosos. Ou seja, as consequências da negligência parental dentro da unidade hospitalar, tendem a se manifestar em prazos significativamente menores, quando comparadas às outras situações de negligência parental, isto porque, caso os pais sejam negligentes com os cuidados de seus filhos no tratamento às doenças crônicas, a possibilidade de vir a óbito é grande.

Outro estudo elaborado pela Psicologia é o da Martins (2006), que em sua dissertação também afirma que a negligência é um dos tipos de violência familiar que mais acometem crianças e adolescentes, porém ressalva que a falta de precisão conceitual da categoria negligência pode acarretar alguns equívocos, visto que há casos que não deveriam ser 
descritos como negligência, "Tal dificuldade faz com que a expressão negligência seja utilizada para nomear diversas situações de violência, bem como para descrever os quadros extremos de pobreza" (MARTINS, 2006, p. 51). Dessa forma, para essa autora,

Pobreza não é sinônimo de negligência. No quadro de desigualdades crônicas no Brasil, nota-se uma grande dificuldade tanto na literatura quanto na prática dos agentes sociais em separar os efeitos da pobreza da negligência doméstica contra crianças. A falta de políticas públicas, a exclusão social, a pobreza estrutural em que se encontram muitas famílias não as tornam negligentes (MARTINS, 2006, p. 58).

Apostólico et al. (2012), sob a perspectiva da enfermagem, realizam um estudo quantitativo, visando caracterizar a violência em uma determinada cidade, além de subsidiar novas políticas públicas. Os autores afirmam que definir casos de negligência é complexo, por envolver aspectos culturais, sociais e econômicos. A aproximação da família e a apreensão da dinâmica familiar podem facilitar a detecção de negligência parental.

No estudo realizado pelas enfermeiras, na maioria dos casos notificados que envolviam situações que envolviam situações de negligência parental, violência física e abandono, foi apreendido que a genitora era a responsável pelos atos. As autoras acreditam que este dado pode ser motivado pelo fato da sociedade atual ter elevado o quantitativo de mulheres chefes de família, ou seja, as relações de gênero desiguais sobrecarregam às mulheres, agregado às condições de pobreza, às jornadas exaustivas de trabalho, ou ao desemprego, além da responsabilidade de cuidar sozinha dos filhos (APOSTÓLICO et al., 2012).

Recentemente, o termo [negligência] vem sendo ampliado para incorporar a chamada supervisão perigosa. É mais frequente em famílias jovens, nas quais a criança está doente e é mantida pela mãe. A uniparentalidade aumenta, em 220\%, o risco de negligência (DAY et al., 2003, p. 13).

Essa análise de Day et al. (2003) a respeito de violência doméstica, corrobora o estudo das enfermeiras, isto é, crianças inseridas em famílias que possuem a mãe como a única mantenedora da residência, correm um maior risco de serem negligenciadas. Pode se pontuar que a desigualdade de renda, e de oportunidades de trabalho, são fatores que influenciam essa realidade.

As enfermeiras Lise e Motta (2012) elaboraram uma revisão sistemática da literatura com o intuito de caracterizar a produção sobre a temática e identificar fatores que tornavam 
o público infantil vulnerável, diferentemente do estudo de Apostólico et al. (2012), identificando as seguintes características dos agressores: maioria do sexo masculino, pai ou padrasto, jovens de baixa escolaridade, a força física foi utilizada como forma de ensinar, usuários de álcool e outras drogas. Além disto, foi recorrente a negação dos fatos por parte da genitora, quando o genitor era o responsável pela violência/negligência.

Após as leituras realizadas percebe-se a ausência de produções textuais na literatura nacional sobre a metodologia a ser utilizada durante uma consulta de enfermagem para reconhecer e intervir em casos de negligência contra crianças e adolescentes. As autoras, referenciando Martins et al. (2007); Pires, Miyazaki (2005); acreditam que isto está interligado a incipiente produção de estudos da Enfermagem para realizar os diagnósticos que envolvem a violência doméstica. Elas ressaltam a falta de conhecimentos sobre a legislação que envolve a temática negligência, bem como, a obrigatoriedade de realizar a notificação de casos suspeitos ou confirmados. Para Lise e Mota (2012, p. 56),

A bibliografia nacional pesquisada não nos permitiu identificar quais são os meios utilizados pelos Enfermeiros para detectar sinais ou sintomas de violência contra crianças e adolescentes que possam contribuir para a investigação de casos de suspeita e a confirmação do diagnóstico.

Essas autoras, ressaltaram a relevância do papel dos enfermeiros no trabalho com crianças e adolescentes vítimas de negligência parental, dentro desta fala é importante pontuar que a enfermagem sempre esteve presente em todos os níveis de atenção à saúde no Brasil, entre outras razões, por esta ramificação dessa profissão os enfermeiros são imprescindíveis no enfrentamento da violência contra crianças e adolescentes.

Não obstante das outras categorias profissionais na área da saúde, fez-se perceptível por meio do estudo de Berberian (2015) a grande necessidade do Serviço Social se aprofundar mais no estudo da categoria negligência. Como já mencionado, a negligência intrafamiliar, e mais especificamente a negligência parental, é um problema de saúde pública, problema este que ainda não está sendo enfrentado com a devida importância por parte das políticas públicas.

\section{Considerações finais}


Com este estudo pode-se perceber o quão necessário é que se realize reflexões, pesquisas, políticas públicas visando aprofundar o conhecimento sobre a categoria negligência; os fundamentos para a produção deste conhecimento devem ser direcionados para a prevenção e promoção da saúde das crianças e dos adolescentes, isto é, prevenir casos que envolvam negligência parental e promover a segurança/ saúde dos que estão sendo vítimas de negligência.

Para intervir no fenômeno da violência é necessário a cooperação de diversas categorias profissionais, na perspectiva da interdisciplinaridade. Esse pode ser um instrumento de trabalho que possibilita avaliações mais abrangentes sobre essa temática. Isso auxiliaria os encaminhamentos necessários de crianças e adolescentes que foram vítimas de quaisquer formas de negligências. Seria lastimável a presença de apenas uma perspectiva sobre o que é negligência dos pais para com seus filhos, pois esta unicidade levaria a uma certa unilateralidade de avaliações, ou seja, o trabalho não alcançaria as diversas manifestações de atos negligentes (BRASIL, 1997).

Foi percebido que ainda se procura uma definição para a categoria negligência, entretanto, acredita-se que esta definição ainda precisa ser melhor definida, visto que ela envolve múltiplos fatores e sua percepção, inicialmente, é subjetiva a cada caso.

Considera-se importante identificar, em casos de negligência, quem é o verdadeiro responsável por este ato de violência, como mencionado por alguns autores neste estudo, condições de pobreza favorecem a existência de negligência às crianças e aos adolescentes, porém não parece lógico responsabilizar pais pobres por não terem realizado alguns exames médicos, ou por não terem comprado algum medicamento para seus filhos, quando estes não estão sendo fornecidos pela rede pública, visto que estes pais podem estar enfrentando dificuldades para manter até a alimentação da família. Isto se trata de negligência sim, mas não de negligência por parte dos pais, e sim de negligência por parte da sociedade e do Estado, em assegurar políticas públicas de assistência social universais. Como preconizado no ECA e na Carta Magna (1988), a responsabilidade para com as crianças e com os adolescentes não é apenas dos pais, e sim do tripé: Estado, sociedade e família. A saúde, a alimentação, educação, entre outros, devem ser fornecidos por este tripé.

A negligência é uma forma de violência que se faz presente em toda a sociedade, independentemente do gênero, idade, ou classe social, mas com base nas reflexões dos 
autores trazidos neste estudo, pôde-se evidenciar que pessoas mais pobres e com menor escolaridade podem expor mais os seus filhos a situações de negligência. Portanto, a valorização de políticas de assistência social; o fornecimento de condições de trabalho para os Conselhos Tutelares; a distribuição de renda; maior escolaridade para os cidadãos, e formação continuada para os trabalhadores da saúde são importantes mecanismos para prevenir e proteger crianças e adolescentes no Brasil.

\section{Referências}

APOSTÓLICO, M. R.; NÓBREGA, C. R.; GUEDES, R. N. et al. Características da violência contra a criança em uma capital brasileira. In: Rev. Latino-Am. Enfermagem. 2012. Disponível em: < http://www.scielo.br/pdf/rlae/v20n2/pt 08>. Acesso em: 10 dez. 2018.

BAZON, M. R.; MELLO, I. L. M. A. de; BERGAMO, L. P. D.; FALEIRO, J. M. Negligência infantil: estudo comparativo do nível socioeconômico, estresse parental e apoio social. In: Temas em Psicologia. 2010, p. 71-84. Disponível em: <http://pepsic.bvsalud.org/ scielo.php?script=sci arttext\&pid=S1413-389X20100007>. Acesso em: 15 de ago. de 2018.

BERBERIAN, T. P. Serviço Social e avaliações de negligência: debates no campo da ética profissional. In: Serviço Social e Sociedade. Mar 2015, n.121, p. 48-65. Disponível em:

$<$ http://www.scielo.br/scielo.php?pid=0048\&script=sci abstract\&tlng=pt $>$. Acesso em: 15 ago. 2018.

BRASIL. Estatuto da Criança e do Adolescente 1990. Brasília: Senado Federal, 2018.

Constituição Federal do Brasil de 1988. Constituição da República Federativa do Brasil. Brasília: Senado Federal, 2015.

Ministério da Saúde. Lygia Maria Pereira da Silva (Org.). Violência doméstica contra à criança $e$ ao adolescente. Recife: Edupe, 2002. 240 p. Disponível em: $<$ http://bvsms.saude.gov.br/bvs/publicacoes/violencia_criancas_adolesc.pdf $>$. Acesso em: 20 jun. 2018

- Ministério da Saúde. Secretaria de Políticas de Saúde. Violência intrafamiliar: orientação para prática em serviços. Brasília: Ministério da Saúde, 2001.

CAMPOS, G. W. de S. A defesa do SUS depende do avanço da reforma sanitária. In: Interface - Comunicação, Saúde, Educação. Botucatu, v. 22, n. 64, p. 5-8, mar. 2018. Fap. UNIFESP (SciELO). Disponível em: <http://www.scielo.br/pdf/icse/v22n64/1807-5762-icse-22-640005.pdf>. Acesso em: 10 dez. 2018. 
DAY, V. P. et al. Violência doméstica e suas diferentes manifestações. Disponível em: Revista de psiquiatria Rio Grande do Sul, Porto Alegre, v. 25, supl. 1, p. 9-21, abril, 2003.

GUERRA, V. N. de A. Violência de pais contra filhos: a tragédia revisitada. 4. ed. São Paulo: Cortez, 2008.

IBGE. Informativo PNAD Contínua 2017 - Rendimento de todas as fontes. Disponível em:

https://biblioteca.ibge.gov.br/visualizacao/livros/liv101559 informativo.pdf. Acesso em: 20 set. 2018.

Síntese de indicadores sociais: uma análise das condições de vida da população brasileira: 2017, Rio de Janeiro. Disponível em: < https://biblioteca.ibge.gov.br/visua lizacao/livros/liv101459.pdf >. Acesso em 20 dez. 2018.

LISE, F.; MOTTA M. da G. C. Violência doméstica infantil: abordagem da enfermagem. Acta Scientiarum. Maringá, v.34, n. 1, p. 53-58, 2012. Universidade Estadual de Maringá. Disponível em: http://periodicos.uem.br/ojs/index.php/ActaSciHealthSci/ar9268/pdf. Acesso em: 12 dez. 2018.

MATA, N. T. Afinal o que é negligência? Um estudo sobre negligência contra crianças [mestrado em Psicologia]. Rio de Janeiro: Escola Nacional de Saúde Pública, 2016. Disponível em:< https://www.arca.fiocruz.br/handle/icict/19468>. Acesso em: 10 dez. 2018.

. N. T. et al. Família e negligência: uma análise do conceito de negligência na infância. In: Ciência \& Saúde Coletiva, Rio de Janeiro, v. 22, n. 9, p. 2881-2888, set. 2017. Disponível em: $<$ http://www.scielo.br/scielo.php?script=sci_abstract\&pid=S1413-8123 2017002902881\&lng=en\&nrm=iso\&tlng=pt>. Acesso em: 11 nov. 2018.

MARTIN, C. Os limites da Proteção da Família. In: Revista Crítica de Ciências Sociais, Coimbra, n.42, p. 53-76, mai. 1995. Disponível em: <Http://www.ces.uc.pt/rccs/ includes/download.php? id=560>. Acesso em: 02 dez. 2018.

OXFAM. Relatório - País estagnado um retrato das desigualdades brasileiras. Oxfam, Brasil, novembro de 2018. Disponível em: <https://www.oxfam.org.br/pais-estagnado>. Acesso em: 31 dez. 2018

PASIAN, M. S.; FALEIROS, J.M.; BAZON, M. R.; LACHARITÁ, C. Negligência Infantil: A Modalidade Mais Recorrente de Maus-tratos. In: Pensando Famílias, vol.17 n.2, p.

61-70, Porto Alegre dez. 2013. Disponível em: <http://pepsic.bvsalud.org/scielo .php?script=sci_arttext\&pid=S1679-494X25>. Acesso em: 18 dez. 2018.

PIRES, A. L. D.; MIYAZAKI, M. C. O. S. Maus-tratos contra crianças e adolescentes: revisão da literatura para profissionais da saúde. In: Revista dos Arquivos das Ciências da Saúde, v. 12, n. 1, p. 42-49, 2005. 
RIBEIRO, M. A. S. C.; BARATA, R. B.; ALMEIDA, M. F. D.; SILVA, Z. P. D.; Perfil sociodemográfico e padrão de utilização de serviços de saúde para usuários e não usuários do SUS- PNAD 2003. In: Ciência \& Saúde Coletiva, São Paulo, p. 10111022, maio 2006. Disponível em: <https://www.scielosp.org/pdf/csc/2006.v11n4/10111022/pt>. Acesso em: 05 ago. 2018.

SEGER, A. C. B. P.; CALDART, P.; GROSSI, P. K. Desvelando a violência contra as crianças em um hospital universitário: desafios para o Serviço Social. Textos \& Contextos, v. 9, n. 1, p. 118131, Porto Alegre, 2010. Disponível em: < http://repositorio.pucrs.br /dspace /bitstream/10923/8074/2/Desvelando a violencia contra_as_criancas_em_um_hospital_u niversitario_desafios_para_o_Servico_Social.pdf>. Acesso em: 08 set. 2018.

SILVA, Z. P. D.; RIBEIRO, M. A. S. C.; BARATA, R. B.; ALMEIDA, M. F. D. Perfil sociodemográfico e padrão de utilização dos serviços de saúde do Sistema Único de

Saúde (SUS), 2003- 2008. In: Ciência \& Saúde Coletiva, [s.I.], v. 16, n. 9, p. 38073816, set. 2011. FapUNIFESP (SciELO). http://dx.doi.org/10.1590/s141381232011001000016. Disponível em: $<H t t p: / / w w w . s c i e l o . b r / s c i e l o . p h p$ script=sciarttext\&pid=6\&lng=en\& $\quad n r m=i s o \& t l n g=p t \quad>$. Acesso em: 06 ago. 2018.

TEIXEIRA, S. M. Política social contemporânea: a família como referência para as Políticas Sociais e para o trabalho social. In: MIOTO, R. C. T.; CAMPOS, M. S.; CARLOTO, C. M. (Orgs.). Familismo Direitos e Cidadania: contradições da política social. São Paulo: Cortez, 2015. 